\title{
Review on Hydrometallurgical Recovery of Metals with Deep Eutectic Solvents
}

\author{
Guillaume Zante ${ }^{1,2, *}$ and Maria Boltoeva ${ }^{1, *}$ (D) \\ 1 Université de Strasbourg, CNRS, IPHC UMR 7178, F-67000 Strasbourg, France \\ 2 ADEME, 20 Avenue du Grésillé, CEDEX 01, 49004 Angers, France \\ * Correspondence: guillaume.zante@etu.unistra.fr (G.Z.); maria.boltoeva@iphc.cnrs.fr (M.B.)
}

Received: 8 September 2020; Accepted: 30 September 2020; Published: 3 October 2020

\begin{abstract}
Deep eutectic solvents (DESs) appeared recently as a new class of green designer solvents. The recovery of metals using hydrometallurgy is of major importance with the growth in metal demand. Several authors used these solvents for the hydrometallurgical recovery of metals from primary and secondary resources, and these studies are reviewed in the present work. Hydrophilic DESs can be used for the leaching of metals and have great potential to replace mineral acids, and even to reduce water consumption. Efficient and selective leaching of metals from minerals or wastes is feasible by using DESs. However, the kinetics of leaching as well as the physicochemical properties of DESs are still limiting their large-scale application. Electrochemical recovery from DES is also possible but deserves further investigation. Finally, the recovery of metals from aqueous solutions using hydrophobic DESs was studied in several works. For the solvent extraction of metals, hydrophobic DESs constitute credible alternative ionic liquids.
\end{abstract}

Keywords: deep eutectic solvents; low temperature transition mixtures; hydrometallurgy; solvent extraction; leaching; electrochemistry; metal extraction; metal recycling

\section{Introduction}

The consumption of metals is increasing with the development and the massification of new technologies, which concerns a growing number of metals from the periodic table [1]. These evolutions are increasing the pressure on the global supply chains, which in turn contributes to risks of scarcity for various metals $[2,3]$. The extraction of metals from primary geological sources as well as recycling from end-of-use consumer goods have to adapt to meet this soaring demand [4,5].

These considerations have major implications for the processes used in the recovery of metals and their impact on the environment in the frame of the global warming threat. As a case study, the recycling of spent lithium-ion batteries (LIBs) in view of metal recovery was intensively studied and the processes applied were compared [6-8]. The pyrometallurgical process consists of smelting the wastes after dismantling which allows us to recover high-purity alloys. However, high temperatures are required and lead to an energy-intensive process. Moreover, several metals are often lost in slags which leads to lower recovery rates than other techniques.

Hydrometallurgical processing allows us to obtain higher recovery rates with a lower consumption of energy and makes possible the treatment of low-concentration aqueous solutions. However, further work is needed to lower the environmental impact of hydrometallurgical processes [9-11].

A representative hydrometallurgical flowsheet for the recovery of metals from spent LIBs is shown in Figure 1. 
The first steps of the process consist of dismantling and grinding the spent battery, with the valuable metals being mainly contained in the smallest fractions [13]. Then, the leaching of these fractions is made to release the metals in an aqueous solution. This leaching step is currently done using mineral acids diluted in water. The separation of the metals is then undertaken with various techniques, from solvent extraction to precipitation.

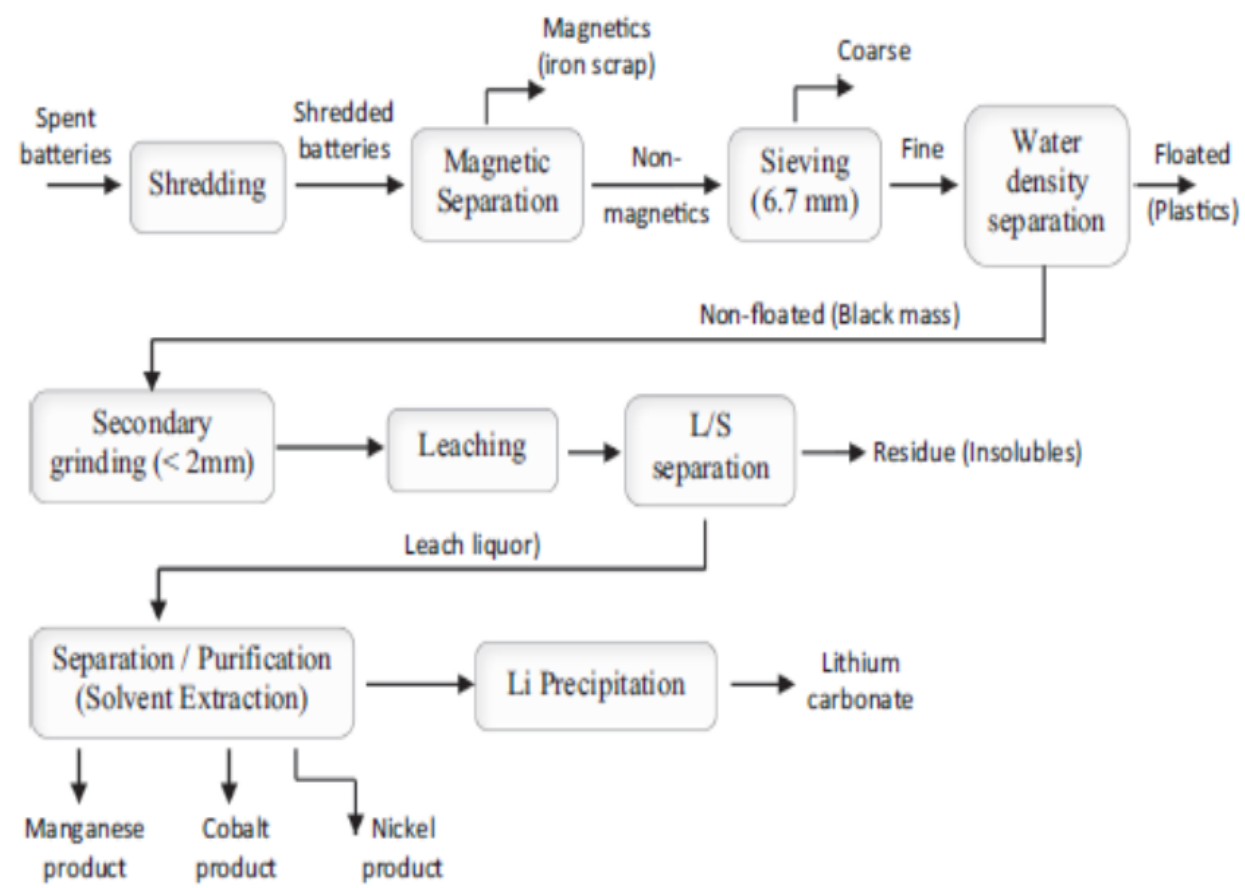

Figure 1. Hydrometallurgical flowsheet for the recovery of metals. Reproduced from [12] with permission from Elsevier.

The leaching step is clearly detrimental from an environmental point of view. The use of mineral acids such as hydrochloric acid has a large contribution to the life cycle analysis of processes [14]. For the recycling of electronic waste, the use of nitric acid was estimated to contribute from $40 \%$ to $80 \%$ to the impact of the process [15]. Thus, replacing these mineral acids is a key aspect to improving the environmental impacts of hydrometallurgical processes.

Another potential method of improvement is the solvent extraction step. Solvent extraction (liquid-liquid extraction) consists of the recovery of metal ions from the aqueous phase using an organic phase, immiscible with water [16]. Solvent extraction is schematized in Figure 2.

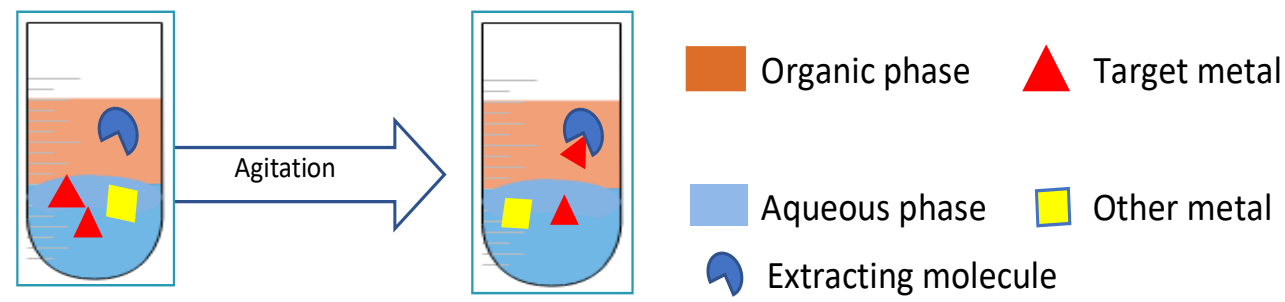

Figure 2. Schematic representation of the solvent extraction.

Generally, the organic phase is made of an organic diluent (typically hydrocarbons such as kerosene) and an extracting molecule (chosen from various families such as organophosphorus compounds, malonamides, quaternary amines, etc.), which both have the lowest aqueous solubility possible. The two immiscible phases, an organic and an aqueous one, are mixed to amplify the area of contact, then separated. After this step, the organic phase is enriched with the target metal ions, 
allowing us to separate several metals in the aqueous phase based on their different affinity for the organic phase.

To improve the transfer of metal ions into the organic phase, the role of the lipophilic extracting molecule is to bind to the metal, usually based on the hard and soft acid and bases (HSAB) theory described by Pearson [17]. Solvent extraction is a mature and widely used technology with numerous advantages such as low operational costs. However, the organic solvents and extracting molecules used in large quantities contribute to the environmental impact of the process. It was demonstrated that the use of organophosphorus extracting molecules (and hydrocarbon solvents to a lower extent) for the processing of rare-earth ores has a huge impact on many environmental aspects (acidification, eutrophication, land use, climate change, the ozone layer, ecotoxicity, etc.) [18].

Deep eutectic solvents (DESs) are a potential tool that can contribute to the design of cleaner processes. The term "DES" refers to a mixture of two (or more) compounds, a hydrogen bond donor (HBD), and a hydrogen bond acceptor (HBA), which has a lower melting point than the melting points of the individual compounds. Abbot et al. [19] reported these new kinds of solvents, composed of choline chloride and urea, in 2003 [20]. For some mixtures of this type, melting point is not observed, but it is essentially a glass transition temperature resulting from the second-order phase transition which gives lieu to what is referred to as a low transition temperature mixture (LTTM) [21]. Florindo et al. ([22]) introduced the definition of hydrophobic eutectic solvents which are defined as "a subclass of DESs where both components are hydrophobic". The authors noted that the term "deep" is sometimes not accurate since there are different depths of eutectic melting points.

These liquids share common properties with ionic liquids (ILs, [23]), but, contrarily to ILs, their synthesis and purification are easier, and they can be made of cheap, affordable, and vastly available HBDs and HBAs. Moreover, some of the DESs are entirely made of natural products (referred to as NADES for natural deep eutectic solvents [24]), and their use could greatly enhance the environmental aspects of the processes designed.

These new eutectic solvents have a huge potential in several fields and one can find multiple reviews for some of their major applications, for example, for water purification, carbon dioxide capture, extraction of target compounds, the design of new pharmaceuticals, etc. [25-33]. However, the use of DESs in hydrometallurgy has not been reviewed yet, while these chemicals have shown promising results in various aspects of this technology.

Firstly, DESs can solubilize metal salts and oxides [34], which make it possible to use them for the leaching of metals from primary or secondary resources to replace conventional leaching roads with acids [35]. Secondly, the DESs have a large electrochemical window, which allows the application of electrochemical techniques such as electrodeposition to refine metals [36-38]. Thirdly, Tereshatov et al. ([39]) envisaged, for the first time, the possibility to use hydrophobic DESs ([40]) for the solvent extraction of metal ions from aqueous solutions. This could constitute one step towards the design of cleaner solvent extraction processes since it would avoid the use of hydrocarbon diluents while using cheap chemicals and without needing any extracting molecule in most cases.

In this review, we aim to provide an overview of the recent advances in the use of both hydrophilic and hydrophobic DESs in the hydrometallurgical process, namely for metal leaching, the electrochemical refining of metals, and the liquid-liquid extraction of metal ions. We also discuss the advantages and drawbacks of DESs application for these steps.

\section{Discussion}

\subsection{DESs for the Leaching of Metals}

The leaching of metals constitutes a major step in every hydrometallurgical process. Leaching allows us to release the metal elements in solution, for which various separation processes can be applied (ion exchange, solvent extraction, chemical precipitation, etc.). The first synthesis of DESs was demonstrated by Abbot et al. [19]. DESs made of choline chloride $(\mathrm{ChCl})$ as an $\mathrm{HBA}$ and of various 
carboxylic acids as HBDs were shown to be able to solubilize various metal oxides. This observation was further confirmed for several metal oxides by the same group with DESs based on various HBDs such as urea, malonic acid (MA), and ethylene glycol (EG) [41]. Interestingly, the solubility of each metal oxide is quite different depending on the DES, which could be used to selectively leach the metals and avoid the expensive separation process to separate each metal from the aqueous solution. The concept of solvometallurgy, defined as the processing of ores or wastes for metal recovery ([42]), is now well established and DESs are emerging for such purpose. Since these first studies, DESs were used as leaching agents for several materials, which are displayed in Table 1 (their structure can be found in Table 2). 
Table 1. Deep eutectic solvents (DESs) used for the leaching of metals in the literature. $\left[\mathrm{P}_{4444}\right][\mathrm{Cl}]$ stands for tetrabutylphosphonium chloride and $\left[\mathrm{N}_{4444}\right][\mathrm{Cl}]$ stands for tetrabutylammonium chloride.

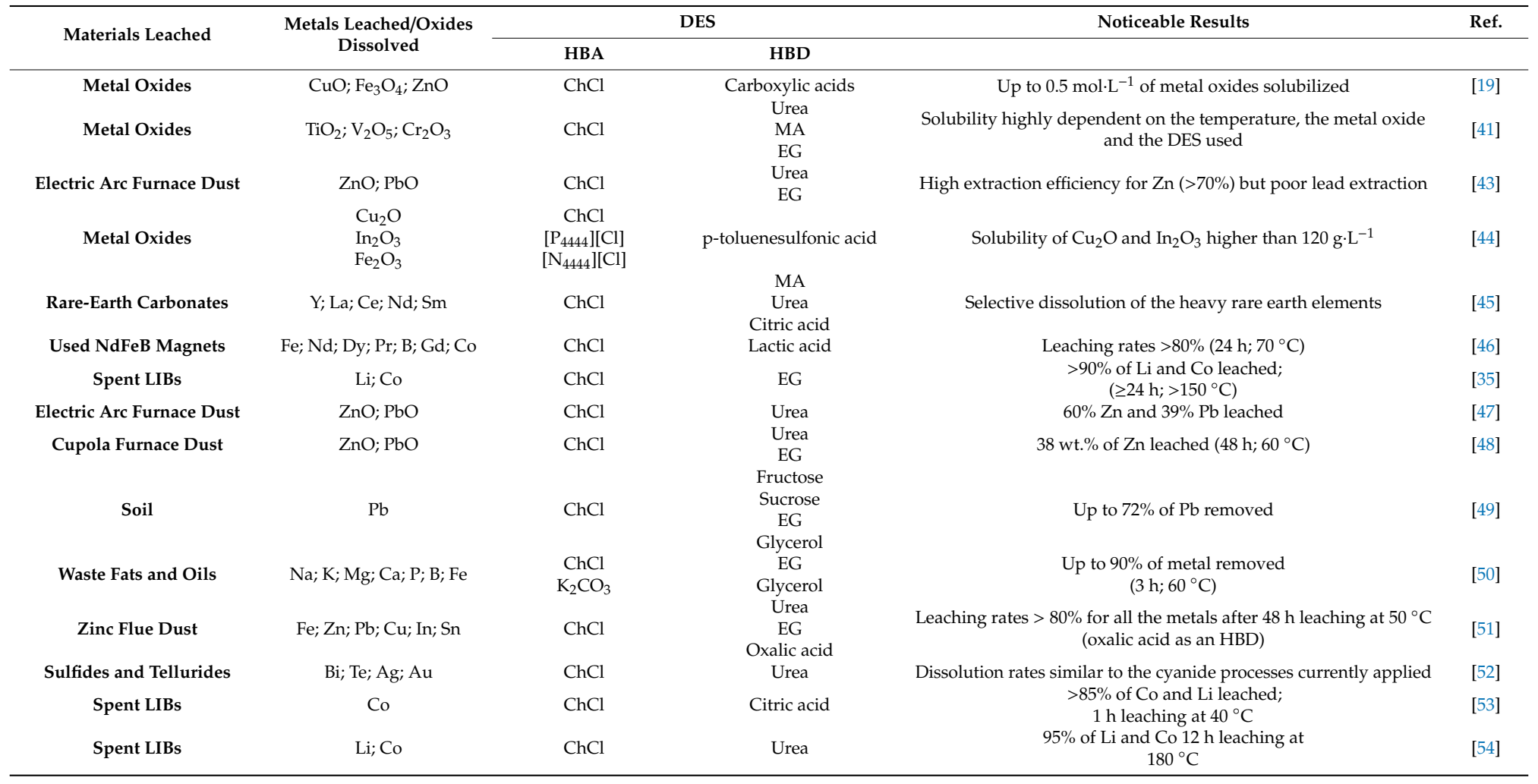


Table 2. Structure of the hydrogen bond donors (HBDs), and hydrogen bond acceptors (HBAs) for the synthesis of DESs used for metal leaching.

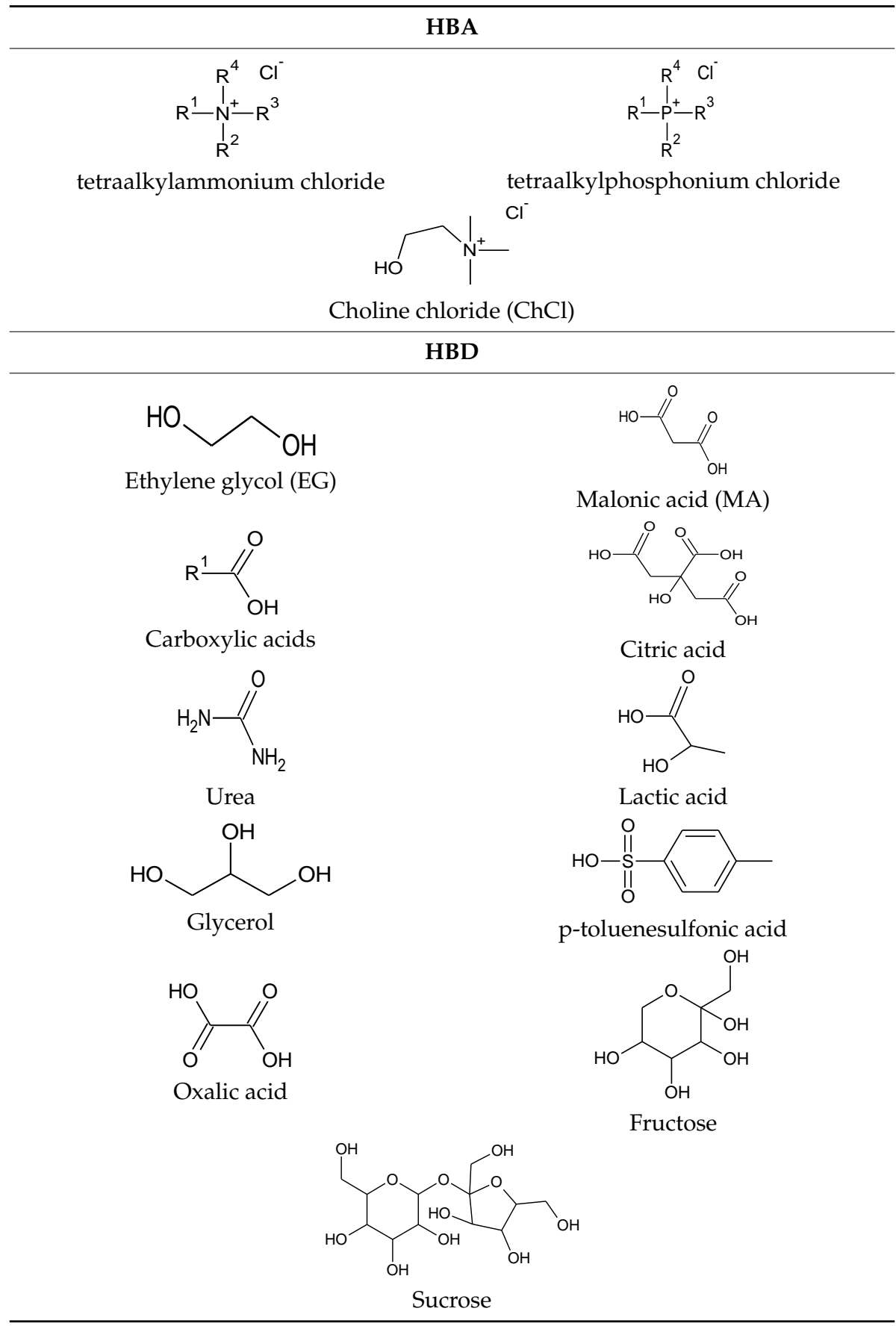

The electric arc furnace process used for the production of steels generates large amounts of dust loaded with toxic metals present as oxides. Several authors demonstrated the possibility to leach these metals from the dust with DESs. The large-scale application of a DES for the processing of these dusts was demonstrated with DESs using $\mathrm{ChCl}$ as an HBA, and urea and $\mathrm{EG}$ as HBDs (1:0.5:2 being the optimal molar ratio for $\mathrm{ChCl}$, urea, and $\mathrm{EG}$, respectively) [43]. The extraction of zinc was efficient and its precipitation as zinc chloride was feasible by adding ammonia to the DES. However, the extraction of lead was lower. Bakkar used similar DESs for the same purpose [47,48]. The processing of the dust allowed the authors to remove most of the Zn by the electrowinning of the DES. As stated by Abbot et al. ([43]), the electrochemical recovery (detailed in the next section) of $\mathrm{Zn}$ from the DES showed 
slow kinetics. The recovery rate of the metals reached high values after several hours, sometimes days, of electrowinning at 50-60 ${ }^{\circ} \mathrm{C}$. Zürner and Frisch ([51]) attempted to recover valuable metals such as indium from this dust. The most efficient DES used was made of oxalic acid as an HBD, which is known for its ability to leach metals when diluted in water [55]. The leaching rates obtained were higher than $80 \%$ for all the metals studied after $48 \mathrm{~h}$ of stirring at $50{ }^{\circ} \mathrm{C}$. The oxalic acid allowed the authors to precipitate metals as oxalates by diluting the DES with water. The precipitation of $\mathrm{Zn}$ and $\mathrm{Pb}$ was achieved directly after the dilution. Next, the precipitation of iron was demonstrated by photoinduced reduction, while the remaining solution contained the valuable metals (Sn and In). Further separation is needed but was not studied.

Another application of DESs is the leaching of metals from discarded electric equipment, commonly referred as waste electronic equipment (WEE). Tran et al. ([35]) used a DES for the leaching of lithium and cobalt from spent lithium-ion batteries. High leaching rates were obtained ( $>90 \%$ for both metals). The color of the DES turned to blue after the leaching, which was attributed to the formation of the $\mathrm{CoCl}_{4}{ }^{2-}$ anion. Thus, leaching of the metals seems to occur via coordination with chloride from the $\mathrm{ChCl} \mathrm{HBA}$. Interestingly, cobalt(III) present in the battery was reduced into cobalt(II), possibly by the EG HBD, and this phenomenon seems to promote leaching. The presence of an oxygen acceptor in the eutectics facilitates the cleavage of the metal oxide bonds, which promotes the digestion of the oxide [41]. Even if high leaching rates are obtained, it should be noted that the kinetics of leaching are slow $\left(24 \mathrm{~h}\right.$ minimum) and high temperatures are needed $\left(>150^{\circ} \mathrm{C}\right)$, while leaching of the same material with nitric acid only takes $2 \mathrm{~h}$ and lower temperatures $\left(65^{\circ} \mathrm{C}\right)$ to obtain similar leaching rates [56].

The same kinetics were reported by Riaño et al. ([46]) for the leaching of metals from used magnets. High leaching rates were obtained after $24 \mathrm{~h}$ of leaching at $70^{\circ} \mathrm{C}$. The leaching rates were much higher when using lactic acid as an HBD rather than urea or EG. The interaction of the oxide with lactic acid $\left(\mathrm{CH}_{3} \mathrm{CHOHCOOH}\right)$ was found to be responsible for the leaching of the metal, according to the following equation:

$$
\mathrm{Nd}_{2} \mathrm{O}_{3}+6 \mathrm{CH}_{3} \mathrm{OHCOOH} \leftrightarrow 2\left(\mathrm{NdCH}_{3} \mathrm{CHOHCOO}\right)_{3}+3\left(\mathrm{H}_{2} \mathrm{O}\right)
$$

The formation of a complex involving neodymium and the deprotonated lactic acid allows us to release the metal from the oxide. Thus, the use of acidic DES ([57]) is favorable in view of metal leaching. As demonstrated by Rodriguez Rodriguez et al. [44], the use of toluene sulfonic acid-based DES could be interesting, since the solubility of some metal oxides in the DES is higher than $120 \mathrm{~g} \cdot \mathrm{L}^{-1}$, which is sometimes higher than a $3 \mathrm{~mol} \cdot \mathrm{L}^{-1} \mathrm{HCl}$ solution. The effect of the DES structure was investigated in this study. Surprisingly, the most acidic DES formed was not the one in which the oxides are more soluble. Several physical and chemical processes affect the leaching efficiency of the DES. Among them, an excessively viscous DES will limit the mass transfer, which has to be considered when designing the DES.

Another possible issue comes from the formation of complexes in the DES. Albler et al. ([58]) found that the formation of cobalt-lactate complexes in the DES inhibits the extraction of cobalt by tri-alkylamines extractants. The DES used for the leaching has to be selected properly to avoid this kind of issue. The formation of Nd-lactic acid complexes was not found to be problematic in the study reported [46]. The authors developed a multistep strategy to recover the metals from the DES phase. $\mathrm{Fe}, \mathrm{B}$ and $\mathrm{Co}$ were first removed using solvent extraction with tricaprylmethylammonium thiocyanate diluted in toluene. B was selectively stripped with EDTA, while Fe and Co were then recovered with $\mathrm{HCl}$ solutions. Dy and Nd were then further separated with the commercial extractant Cyanex 923, allowing the authors to recover rare-earth oxides with high purity $(>99.8 \%)$.

Hydrophilic DESs were also used to wash metals from hydrophobic streams like waste fat and oils ([50]) and the method was found to be promising, with the results obtained similar to conventional adsorbents. Another potential use of DES is the depollution of soils contaminated with heavy metals [49]. Natural DESs based on fructose or sucrose and $\mathrm{ChCl}$ were able to remove $\mathrm{Pb}$ from the soil. The DES acts as a $\mathrm{H}^{+}$supplier that could replace $\mathrm{Pb}$ from the organic carbon-containing soil. 
The examples of metal leaching from rocks are not numerous. Jenkin et al. ([52]) used DESs for the leaching of gold-bearing ores and other minerals. The authors showed that selective dissolution could be obtained by electrolysis of the DES. The dissolution rates obtained were satisfying, and the method much more environmentally friendly than the cyanidation processes used for the same purpose.

An interesting property of the DES comes from the different solubility of the metals, which could be used for their separation. The different solubilities were illustrated by the different solubility of various sodium salts in DESs [59]. Entezari-Zahandi and Larachi ([45]) used this characteristic to separate heavy rare-earth elements from lighter rare-earth elements, the former being more soluble in the DES than the latter.

Wang et al. studied the behavior of various DESs using electrochemical techniques in order to define relevant leaching agents for spent LIBs [54]. The role of urea as a reducing agent was found to be essential to promote the leaching of the metals. By increasing the temperature to $180{ }^{\circ} \mathrm{C}$, high leaching rates $(95 \%)$ were obtained for both $\mathrm{Co}$ and $\mathrm{Li}$; Co was then precipitated in the DES. However, the time needed for leaching remained long (12 h) and the temperature high compared to leaching using minerals acids. The temperature and time required are much lower when using leaching agents such as citric or oxalic acid. Peeters et al. used a DES made of $\mathrm{ChCl}$ and citric acid to leach spent LIBs [53]. In this case, $\mathrm{Cu}$ was found to be an appropriate reducing agent for $\mathrm{Co}(\mathrm{III})$, which favors the leaching of Co. Interestingly, $\mathrm{Cu}$ comes from the current collectors of the spent LIBs, which does not require any added reagents. Cobalt in the DES phase was found to exist predominantly in the form of chloro-cobalt complexes due to the interaction with the chloride anion from choline chloride. Copper and cobalt were then subsequently purified using solvent extraction. The use of the DES allowed the authors to avoid the release of chlorine gas, which is a major issue when using hydrochloric acid.

There are several ways to improve the leaching of metals by DESs. A comprehensive investigation of the complex physical and chemical phenomena occurring during the leaching could help to design new DESs that are able to dissolve metals efficiently and quickly. A major drawback comes from the slowness of the leaching, which sometimes requires several days of mixing. The proper selection of the HBDs and HBAs is needed to avoid viscous DESs and to simplify the next steps of purification which comes after the leaching. The use of HBDs and HBAs able to leach the metals such as citric, oxalic, or lactic acid seems to be a better option. HBDs and HBAs that are able to reduce metals are also useful in some cases. The corrosivity and long-term behavior of these products have to be determined to allow their application.

\subsection{DESs for the Electrochemical Recovery of Metals}

The study of Gupta et al. ([60]) investigated the behavior of uranyl ions $\left(\mathrm{UO}_{2}{ }^{2+}\right)$ dissolved in a DES made of $\mathrm{ChCl}$ and urea. The interaction between uranium and the DES was found to modify its redox behavior, which was studied by electrochemical techniques such as voltammetry. The results indicated that the water content did not affect the structure of the DES but contributed to the stabilization of the unstable pentavalent $\mathrm{UO}_{2}{ }^{+}$. Water content and complexation with both urea and chloride in the DES lead to changes in uranium speciation. These aspects have to be considered for the electrochemical recovery of metals from DES, which was intensively studied recently. Some of these works are displayed in the following table (Table 3).

Poll et al. ([61]) studied the recycling of lead from hybrid perovskites used for the photovoltaic production of electricity. The powdered materials were found to be entirely dissolved in the DES solution, and spectroscopic studies showed that $\mathrm{Pb}$ was involved in a $\mathrm{PbCl}_{3}{ }^{-}$complex with $\mathrm{ChCl} \mathrm{HBA}$. Then, the selective recovery of lead was undertaken by using a Pb working electrode, allowing the authors to recover high-purity $\mathrm{Pb}$. In total, 99.8\% of the lead was removed from the DES with $120 \mathrm{~h}$ of electrodeposition, using a potential of $-0.9 \mathrm{~V}$ vs. Ag. 
Table 3. DESs used for the electrochemical recovery of metals.

\begin{tabular}{|c|c|c|c|c|c|}
\hline \multirow{2}{*}{ Purpose of the Study } & \multirow{2}{*}{$\begin{array}{c}\text { Metals } \\
\text { Investigated }\end{array}$} & \multicolumn{2}{|c|}{ DES } & \multirow{2}{*}{$\begin{array}{c}\text { Method } \\
\text { Employed }\end{array}$} & \multirow{2}{*}{ Reference } \\
\hline & & HBA & HBD & & \\
\hline $\begin{array}{l}\text { Understand the behavior of actinide } \\
\text { ions in DES media }\end{array}$ & $\mathrm{UO}_{2}{ }^{2+}$ & $\mathrm{ChCl}$ & Urea & Voltammetry & [60] \\
\hline $\begin{array}{l}\text { Recovery of lead from hybrid } \\
\text { organic-inorganic perovskites }\end{array}$ & $\mathrm{Pb}$ & $\mathrm{ChCl}$ & EG & Electrodeposition & [61] \\
\hline $\begin{array}{c}\text { Removal of } \mathrm{Zn} \text { from electric arc } \\
\text { furnace dust }\end{array}$ & $\mathrm{ZnO} ; \mathrm{PbO}$ & $\mathrm{ChCl}$ & Urea & Electrodeposition & {$[47]$} \\
\hline $\begin{array}{c}\text { Removal of } \mathrm{Zn} \text { and } \mathrm{Pb} \text { from electric } \\
\text { arc furnace dust }\end{array}$ & $\mathrm{ZnO} ; \mathrm{PbO}$ & $\mathrm{ChCl}$ & $\begin{array}{l}\text { Urea } \\
\text { EG }\end{array}$ & Electrodeposition & [48] \\
\hline $\begin{array}{l}\text { Recovery of tungsten and arsenic } \\
\text { from secondary mine resource }\end{array}$ & W; As & $\mathrm{ChCl}$ & $\begin{array}{c}\text { MA } \\
\text { Oxalic acid }\end{array}$ & Electrodialysis & [62] \\
\hline
\end{tabular}

The same strategy was applied to the removal of $\mathrm{Zn}$ and $\mathrm{Pb}$ from electric arc furnace dust $([47,48])$. As already described, the dust was first dissolved in the DES, allowing the authors to dissolve most of $\mathrm{Zn}$ and lower amounts of $\mathrm{Pb}$. Then, the electrochemical behavior of $\mathrm{Zn}$ was established using cyclic voltammetry [48]. The results showed that the water dissociation in the DES and the decomposition of the DES contribute to decreasing the current efficiency, which could be a limitation to the use of DESs for these purposes. Then, $\mathrm{Zn}$ was electrodeposited with a working potential of $-1.5 \mathrm{~V} \mathrm{vs}$. Ag, and it was shown that this process is limited by the diffusion of $\mathrm{Zn}$ ions in the DES [63]. The recovery of high-purity $\mathrm{Zn}$ is possible with this technique and was also demonstrated for lead [47].

Another example comes from the recovery of $W$ and As from secondary mine resources [62]. An electrodialysis system was designed by the authors, composed of two compartments separated by an anion exchange membrane. The first compartment contained the mining residue mixed with the DES; the second compartment was made of an anolyte $\left(\mathrm{NaNO}_{3}\right.$ in distilled water). The application of a potential difference between both compartments allowed the migration of anionic species of $\mathrm{W}$ and As through the membrane. In total, $82 \%$ of As and $77 \%$ of $\mathrm{W}$ were recovered using a current of $100 \mathrm{~mA}$ for 4 days. The DESs allowed, firstly, the leaching of the metals from the mining residue and, secondly, their transfer due to their electrochemical window.

The recovery of metals via the application of electrochemical techniques in DES appears to be promising. However, the current efficiency was found to be poor in some cases [43] and sometimes requires long periods to recover the metals. The application of ultrasounds, for example, can increase the mass transfer and improve the electrochemical processes [64]. The diffusion of metallic species through the DES to the electrode appears to be a limitation, evidencing the advantage of using lowly viscous DESs. The water content and decomposition of the DES during the application of a current lead to a decrease in current efficiency, which appears to be a clear limitation and deserves further investigation.

\subsection{Hydrophobic DESs for the Solvent Extraction of Metals}

In the works previously described, the DESs were hydrophilic and completely miscible with water. Many hydrophobic DESs (with limited solubility in water) have been described and characterized [65] and could be of great help to replace conventional diluents for the solvent extraction of metals. The works based on hydrophobic DESs for this purpose are displayed in the following table (Table 4); the structure of the HBDs and HBAs can be seen in Table 5 .

Table 4. Hydrophobic DESs used for the solvent extraction of metal ions.

\begin{tabular}{|c|c|c|c|}
\hline \multirow{2}{*}{ Target Metals } & \multicolumn{2}{|l|}{ DES } & \multirow{2}{*}{ Reference } \\
\hline & HBA & HBD & \\
\hline $\operatorname{In}(\mathrm{III})$ & $\begin{array}{l}\text { Tetraheptylammonium chloride } \\
\text { DL-menthol }\end{array}$ & $\begin{array}{c}\text { Dodecanoic acid } \\
\text { Decanoic acid } \\
\text { Oleic acid } \\
\text { Ibuprofen }\end{array}$ & [39] \\
\hline
\end{tabular}


Table 4. Cont.

\begin{tabular}{|c|c|c|c|}
\hline \multirow{2}{*}{ Target Metals } & \multicolumn{2}{|l|}{ DES } & \multirow{2}{*}{ Reference } \\
\hline & HBA & HBD & \\
\hline $\mathrm{Cr}(\mathrm{VI})$ & $\begin{array}{l}\text { Trioctylmethylammonium } \\
\text { chloride }\end{array}$ & $\begin{array}{c}\text { methyl } \\
\text { 4-hydroxybenzoate } \\
\text { butyl 4-hydroxybenzoate } \\
\text { isobutyl } \\
\text { 4-hydroxybenzoate } \\
\text { n-octyl } \\
\text { 4-hydroxybenzoate } \\
\text { 2-ethylhexyl } \\
\text { 4-hydroxybenzoate }\end{array}$ & [66] \\
\hline $\mathrm{Cr}(\mathrm{VI})$ & Tetrabutylammonium chloride & Decanoic acid & [67] \\
\hline $\begin{array}{l}\mathrm{Tc}(\mathrm{VII}) \\
\operatorname{Re}(\mathrm{VII})\end{array}$ & $\begin{array}{c}\text { Tetra-alkyl ammonium bromides } \\
\text { Tetra-alkyl phosphonium } \\
\text { chloride }\end{array}$ & $\begin{array}{l}\text { Decanoic acid } \\
\text { Hexanoic acid }\end{array}$ & [68] \\
\hline $\begin{array}{l}\text { Alkali and transition } \\
\text { metal ions }\end{array}$ & Lidocaine & Decanoic acid & [69] \\
\hline $\mathrm{Fe}(\mathrm{III}) ; \mathrm{Mn}(\mathrm{II})$ & $\begin{array}{c}\text { Lidocaine } \\
\text { Trioctylphosphine oxide }\end{array}$ & Decanoic acid & [70] \\
\hline Pt(IV); Pd(II); Fe(III) & $\begin{array}{l}\text { Thymol } \\
\text { Hydrocinnamic acid }\end{array}$ & Capric acid & [71] \\
\hline $\mathrm{Cu}(\mathrm{II})$ & $\begin{array}{c}\text { Thymol } \\
\text { Menthol }\end{array}$ & Carboxylic acids & [72] \\
\hline $\mathrm{U}(\mathrm{VI})$ & $\begin{array}{l}\text { Trioctylphosphine oxide } \\
\text { Tetrabutylammonium chloride }\end{array}$ & Phenol & [73] \\
\hline $\mathrm{Co}(\mathrm{II})$ & $\begin{array}{c}\text { Trioctylmethylammonium } \\
\text { chloride } \\
\mathrm{ChCl}\end{array}$ & Phenol & [74] \\
\hline
\end{tabular}

Table 5. Structure of the HBAs and HBDs used for the synthesis of hydrophobic DESs for the solvent extraction of metal ions.

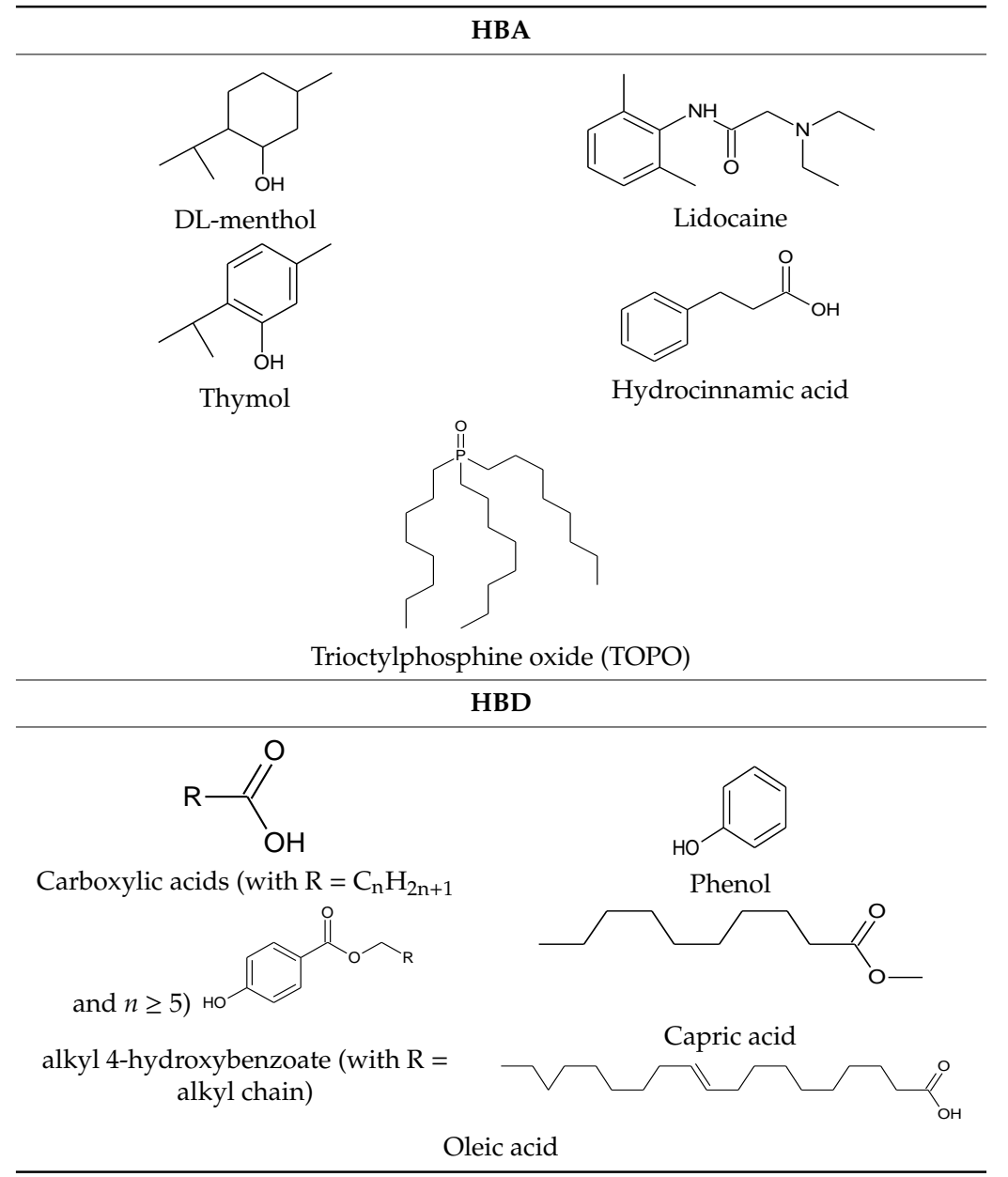


Tereshatov et al. ([39]) were the first to evidence the extraction of metals (indium and thallium) from aqueous hydrochloric acid solutions to undiluted DESs. With DESs based on tetraheptylammonium chloride (abbreviated as $\left[\mathrm{N}_{7777}\right][\mathrm{Cl}]$ ), the metal extraction is similar to what is obtained with quaternary amines extracting molecules. The anionic complexes of the metal formed in the aqueous phase are extracted by the cationic amine, which occurs in several steps. First, the authors assume that part of the DES is solubilized in water and gets ionized, as described in the following equation for the DES made of $\left[\mathrm{N}_{7777}\right][\mathrm{Cl}]$ as an $\mathrm{HBA}$ and carboxylic acid $(\mathrm{RCOOH})$ as an $\mathrm{HBD}$ :

$$
\left(\mathrm{N}_{7777} \bullet \bullet \bullet \bullet \mathrm{Cl} \bullet \bullet \bullet H \bullet \bullet \bullet \bullet O C R\right)_{\mathrm{DES}} \leftrightarrow\left(\mathrm{N}^{+}{ }_{7777}\right)_{\mathrm{aq}}+\left(\mathrm{Cl}^{-}\right)_{\mathrm{aq}}+\left(\mathrm{H}^{+}\right)_{\mathrm{aq}}+\left(\mathrm{RCOO}^{-}\right)_{\mathrm{aq}}
$$

where the subscripts "DES" and "aq" refer to the DES phase and the aqueous phase, respectively. The cationic moiety and the anionic complexes formed between the metal and the chloride anion $\left(\mathrm{MCl}_{x}^{(n-x)-}\right)$ can then be extracted to the DESs, according to the following equation:

$$
\left(\left(M C l_{x}^{(n-x)-}\right)_{a q}+(n-x)\left(N_{7777}^{+}\right)_{a q} \leftrightarrow\left(N_{7777}^{+}\right)_{n-x}\left(M C l_{x}^{(n-x)-}\right)_{D E S}\right.
$$

The extraction of anionic complexes with these DESs is likely to occur in hydrochloric acid media. Interestingly, the same DES is also able to extract metals via a different mechanism thanks to carboxylic acid, according to the following equation:

$$
\left(\mathrm{M}^{n+}\right)_{a q}+n\left(\mathrm{RCOO}^{-}\right)_{a q} \leftrightarrow\left(\mathrm{M}(\mathrm{RCOO})_{n}\right)_{D E S}
$$

The carboxylic acids allowed the extraction of cationic species. Since this mechanism requires the deprotonation of the carboxylic acid, the $\mathrm{pH}$ of the aqueous phase should be lowly acidic. As exemplarily shown in this study, a DES made of entirely natural products such as DL-menthol as an HBA and lauric acid as an HBD gave satisfying results with high extraction efficiency for indium in both hydrochloric and oxalic acid media.

Ruggeri et al. ([67]) demonstrated the extraction of $\mathrm{Cr}(\mathrm{VI})$ from aqueous media with DESs based on decanoic acid. The recovery of the metal from the DES was shown to be possible using electrochemistry. The water content in the DES was studied and it was shown that a small water content is beneficial since it has a large effect on both the DES viscosity and the electrical conductivity. $\mathrm{Cr}(\mathrm{VI})$ extraction was efficient, but it should be noted that the extraction of other metals such as $\mathrm{Cu}$ (II) or $\mathrm{Ni}$ (II) lead to the jellification of the DES. Thus, attention should be paid to the modification of the DES structure induced by metal extraction, which could create practical problems such as the jellification of the DES phase.

Phelps et al. ([68]) used quaternary ammonium and phosphonium cations as HBA to remove Tc from aqueous phases, which could be helpful for nuclear fuel cycle applications and the purification of medicinal radioisotopes. The extraction of trace levels of $\mathrm{TcO}_{4}{ }^{-}$was quantitative with the DESs investigated and can be done with small volumes of DES compared to the aqueous phase volume. However, some limits were outlined in the study. The back extraction of the metal from the DES phase was found to be possible but difficult. The presence of rhenium $\left(\mathrm{ReO}_{4}{ }^{-}\right)$in the aqueous phase competed with technetium, thus suppressing its extraction, and sometimes inducing the occurrence of precipitates in the DES phase.

Van Osch et al. ([69]) used DESs based on carboxylic acids for the removal of transition and alkali metal ions. The extraction was dependent on the HBA:HBD molar ratio but was found to be efficient for transition metal ions (extraction rates $>99 \%$ ) due to the particular affinity of carboxylic acids for these metals [75]. However, lidocaine was used as an HBA, which could be problematic. It was found that the extraction of metals occurred via the exchange of the protonated lidocaine with the extracted metal. Thus, the aqueous phase after extraction should contain a high level of organic molecules which could lead to environmental issues and would probably require wastewater treatment. These problems highlight the necessity of designing DESs with the lowest possible solubility in water. The authors obtained the complete stripping of the metal and the regeneration of the DESs with 
sodium carbonate solutions. The DES could be re-used with similar performances, but only if the DES contains an initially high content of decanoic acid (molar ratio lidocaine: decanoic acid $=1: 4$ and 1:3). The molar ratio of the DES is therefore an important parameter since it affects the efficiency and the physicochemical properties of the DES. Molar ratios that favors low viscosity and low solubility in water should be preferred.

Attention should also be paid to the mechanism of extraction to avoid the pollution of the aqueous phase. Ola and Matsumoto ([70]) used the same DES (lidocaine and decanoic acid) for the separation of iron from manganese. Depending on the $\mathrm{pH}$, it was found that the extraction could occur by exchange with lidocaine or ion pair formation with decanoic acid, the latter being more favorable since it limits the pollution of the aqueous phase. The authors obtained, in this study, a high extractability of iron ( $100 \%$ for 10 mmol.L $\mathrm{L}^{-1}$ of iron) and a high separability from manganese (separation factors $>100$ ).

Gilmore et al. ([73]) introduced the idea of liquefying conventional extracting molecules by using them in DESs. Tri-octylphosphine oxide (TOPO) has a low solubility in conventional molecular diluents $\left(0.1-0.2 \mathrm{~mol} \cdot \mathrm{L}^{-1}\right.$ in kerosene [73]), which limits its use, but it has a low melting point (around $52{ }^{\circ} \mathrm{C}$ [73]). Thus, it can be used as an HBA in combination with phenol, for example, and the DES formed showed a high extractability of uranium in nitrate media. Using extracting molecules as HBDs or HBAs appears to be promising: these molecules have a high complexation ability, a usually low solubility in water, and can be found in various families ( $\beta$-diketones, for example, have usually a low melting point, complexation ability and can be involved in hydrogen bonding [76]). However, the long-term behavior of these DESs is yet to be determined (corrosivity, degradation). With the amount of TOPO in these DESs being high, the management of waste DESs could also be problematic, particularly for the incineration of phosphorus-containing wastes.

TOPO-based DESs were also used for the recovery of acids [77] and the extraction of $\mathrm{Pt}, \mathrm{Pd}, \mathrm{Cu}$, and Fe [71]. When the solvating extractant TOPO is the main component of the DES, the metal is more likely extracted with its counter anion $\left(\mathrm{X}^{-}\right)$according to the following equation:

$$
\left(M^{n+}\right)_{a q}+\left(\mathrm{X}^{-}\right)_{a q}+x(\mathrm{TOPO})_{D E S} \leftrightarrow\left(M X_{n}(\mathrm{TOPO})_{x}\right)_{D E S}
$$

This mechanism requires the presence of a sufficiently high level of anionic species to maintain electrical neutrality. In the same study ([71]), acidic molecules such as capric acid or hydrocinnamic acid were used either as HBAs or HBDs. In this case, the extraction occurs by exchange with the labile proton, as described in Equation (3). When both TOPO and an acid comprise the DES, the preferred mechanism of extraction is unclear and depends on several factors, such as acid concentration in the aqueous phase or HBA:HBD molar ratio. It should also be noted that complexes involving both the HBA and the HBD are probably formed in the aqueous phase, which raises the question of the evolution of the DES and its re-usability since its structure is completely modified during the extraction.

In view of improving the environmental benefits of using DESs, the same group described entirely natural hydrophobic DESs made of terpenes for the extraction of $\mathrm{Cu}$ [72]. The work reported a high extraction efficiency, particularly for $\mathrm{Cu}, \mathrm{Fe}$, and $\mathrm{Zn}$, when using decanoic acid combined with thymol or menthol. However, the extraction was highly dependent on the initial concentration of the metal. When $\mathrm{Cu}$ concentration was lower than $0.01 \mathrm{~mol} \cdot \mathrm{L}^{-1}$, the extraction rates were higher than $90 \%$, but extraction rates dropped to values lower than $50 \%$ when the initial concentration of $\mathrm{Cu}$ was $0.020 \mathrm{~mol} \cdot \mathrm{L}^{-1}$.

Shi et al. ([66]) designed DESs based on trioctylmethylammonium chloride as an HBA and parabens of various alkyl chains as HBDs. It was found that the $\mathrm{HCrO}_{4}{ }^{-}$species was extracted by the quaternary amine in a similar extraction mechanism as that described in Equation (2). The chromium extraction method described was found to be satisfying for the determination of a low concentration of chromium in natural waters.

Another possibility is to use DESs as hydrophobic solvents for the microextraction of metals. Arain et al. ([74]) used several DESs as solvents, while 1-nitroso-2-naphtol was used to extract cobalt 
prior to its determination. In this study, the recovery and accurate determination of cobalt were achieved, highlighting the possibility of using DESs for analytical applications.

Several works demonstrated the possibility of using hydrophobic DESs for the solvent extraction of metals. Most of the DESs reported are hydrophilic and hydrophobic DESs have emerged in the last five years [78]. The properties of DESs for the solvent extraction of metals are still limited by their intrinsic properties, particularly their high viscosity, but there is still room for the design of new DESs that could ameliorate the environmental aspects of solvent extraction while being of practical use. The cation exchange mechanism leads to the contamination of the aqueous phase and should be avoided. The high solubility in water of the DESs is also problematic. The addition of salts in the aqueous phase is known to modify the solubility of ionic liquids ([79]) and could be investigated in the case of DESs. Compared to ionic liquids, DESs seems to have a lower toxicity [80]. However, a complete and comparative life cycle analysis could be useful to clearly evaluate the environmental benefits of DESs.

\section{Conclusions}

DESs have found applications in various domains of hydrometallurgy. The "green" aspect of DESs is promising in this domain and many works envisaged the application of processes for the recovery of metals with a limited impact on the environment, for example, by replacing mineral acids in the leaching steps with hydrophilic DESs or replacing conventional hydrocarbon diluents with hydrophobic DESs.

For the leaching of metals from various materials, DESs are promising since several works reported a high leaching efficiency using cheap, available, and environmentally friendly HBDs and HBAs. Another advantage of DESs comes from the possibility to selectively leach metals by using different solubilities of metals in the DES. However, there is still a long way to go to reach the replacement of mineral acids by DESs. The fundamental aspects of leaching using DESs deserve a better understanding, and the comprehension of the physicochemical processes of leaching in these liquids could help to properly select the HBDs and HBAs that are adequate for this purpose. The main issue comes from the slowness of the leaching, which takes several hours using DESs, and has to be faster to be applied at an industrial scale.

DESs allow the electrochemical recovery of metals, which was studied by several groups. In this case, too, the slowness of the process is limiting its viability and further work is needed to improve the electrochemical recovery of metals from DESs. The selection of lowly viscous DESs seems to be mandatory to favor the kinetics of mass transfer.

For the solvent extraction of metals, several hydrophobic DESs were applied and have great potential to replace conventional diluents and extractants. However, there are some limitations to the large-scale application of DES in solvent extraction processes, which are mainly related to the properties of DES. Highly viscous DESs will slow down the kinetics of mass transfer, which makes their use impractical. A hygroscopic DES (able to incorporate large amounts of water in its structure) will also be difficult to manage. The solubility of the HBAs and HBDs in water has also to be as low as possible to avoid costly wastewater treatment after the solvent extraction procedure. In view of these issues, the use of extracting molecules as HBDs and HBAs is favorable since these molecules usually have low solubility in water while also being able to extract metals. Some potential issues have to be investigated to allow the industrial application of DESs, such as their long-term behavior and corrosivity. One should also consider that the introduction of the metal could modify the structure of the DES and consequently have an effect on its properties and potential reusability.

Author Contributions: Investigation, G.Z. and M.B.; writing-original draft preparation, G.Z. and M.B.; writing-review and editing, G.Z. and M.B.; supervision, M.B.; project administration, M.B. funding acquisition, M.B. All authors have read and agreed to the published version of the manuscript.

Funding: This research was funded by Agence de l'Environnement et de la Maîtrise de l'Énergie (ADEME). 
Acknowledgments: The financial support from the French Environment \& Energy Management Agency (Agence de l'Environnement et de la Maîtrise de l'Énergie, ADEME, fellowship to GZ) is gratefully acknowledged.

Conflicts of Interest: The authors declare no conflict of interest.

\section{Abbreviations}

$\begin{array}{ll}\text { LIBs } & \text { Lithium-ion batteries } \\ \text { DESs } & \text { Deep eutectic solvents } \\ \text { LTTMs } & \text { Low-temperature transition mixtures } \\ \text { HBA } & \text { Hydrogen bond acceptor } \\ \mathrm{HBD} & \text { Hydrogen bond donor } \\ \mathrm{ChCl} & \text { Choline chloride } \\ \mathrm{MA} & \text { Malonic acid } \\ \text { EG } & \text { Ethylene glycol } \\ {\left[\mathrm{N}_{4444}\right][\mathrm{Cl}]} & \text { Tetrabutylammonium chloride } \\ {\left[\mathrm{P}_{4444}\right][\mathrm{Cl}]} & \text { Tetrabutylphosphonium chloride } \\ {\left[\mathrm{N}_{7777}\right][\mathrm{Cl}]} & \text { Tetraheptylammonium chloride } \\ \text { TOPO } & \text { Trioctylphosphine oxide }\end{array}$

\section{References}

1. Halada, K.; Shimada, M.; Ijima, K. Forecasting of the Consumption of Metals up to 2050. Mater. Trans. 2008, 49, 402-410. [CrossRef]

2. Henckens, M.L.C.M.; Driessen, P.P.J.; Worrell, E. Metal scarcity and sustainability, analyzing the necessity to reduce the extraction of scarce metals. Resour. Conserv. Recycl. 2014, 93, 1-8. [CrossRef]

3. Sverdrup, H.U. Modelling global extraction, supply, price and depletion of the extractable geological resources with the LITHIUM model. Resour. Conserv. Recycl. 2016, 114, 112-129. [CrossRef]

4. Sverdrup, H.U.; Ragnarsdottir, K.V.; Koca, D. An assessment of metal supply sustainability as an input to policy: Security of supply extraction rates, stocks-in-use, recycling, and risk of scarcity. J. Clean. Prod. 2017, 140, 359-372. [CrossRef]

5. Legarth, J.B. Sustainable metal resource management-The need for industrial development: Efficiency improvement demands on metal resource management to enable a (sustainable) supply until 2050. J. Clean. Prod. 1996, 4, 97-104. [CrossRef]

6. Belchí Lorente, D.; Mandil, G.; Svecova, L.; Thivel, X.-P.; Zwolinski, P. Life Cycle and Sustainability. In Lithium Process Chemistry; Elsevier: Amsterdam, The Netherlands, 2015; pp. 269-288. [CrossRef]

7. Zheng, X.; Zhu, Z.; Lin, X.; Zhang, Y.; He, Y.; Cao, H.; Sun, Z. A Mini-Review on Metal Recycling from Spent Lithium Ion Batteries. Engineering 2018, 4, 361-370. [CrossRef]

8. Mossali, E.; Picone, N.; Gentilini, L.; Rodrìguez, O.; Pérez, J.M.; Colledani, M. Lithium-ion batteries towards circular economy: A literature review of opportunities and issues of recycling treatments. J. Environ. Manag. 2020, 264, 110500. [CrossRef]

9. Boyden, A.; Soo, V.K.; Doolan, M. The Environmental Impacts of Recycling Portable Lithium-Ion Batteries. Procedia CIRP 2016, 48, 188-193. [CrossRef]

10. Qi, C.; Ye, L.; Ma, X.; Yang, D.; Hong, J. Life cycle assessment of the hydrometallurgical zinc production chain in China. J. Clean. Prod. 2017, 156, 451-458. [CrossRef]

11. Norgate, T.E.; Jahanshahi, S.; Rankin, W.J. Assessing the environmental impact of metal production processes. J. Clean. Prod. 2007, 15, 838-848. [CrossRef]

12. Vieceli, N.; Nogueira, C.A.; Guimarães, C.; Pereira, M.F.C.; Durão, F.O.; Margarido, F. Hydrometallurgical recycling of lithium-ion batteries by reductive leaching with sodium metabisulphite. Waste Manag. 2018, 71, 350-361. [CrossRef] [PubMed]

13. Zhang, T.; He, Y.; Wang, F.; Ge, L.; Zhu, X.; Li, H. Chemical and process mineralogical characterizations of spent lithium-ion batteries: An approach by multi-analytical techniques. Waste Manag. 2014, 34, 1051-1058. [CrossRef] [PubMed] 
14. Li, Z.; Diaz, L.A.; Yang, Z.; Jin, H.; Lister, T.E.; Vahidi, E.; Zhao, F. Comparative life cycle analysis for value recovery of precious metals and rare earth elements from electronic waste. Resour. Conserv. Recycl. 2019, 149, 20-30. [CrossRef]

15. Iannicelli-Zubiani, E.M.; Giani, M.I.; Recanati, F.; Dotelli, G.; Puricelli, S.; Cristiani, C. Environmental impacts of a hydrometallurgical process for electronic waste treatment: A life cycle assessment case study. J. Clean. Prod. 2017, 140, 1204-1216. [CrossRef]

16. Rydberg, J.; Cox, M.; Musikas, C.; Choppin, G.R. Solvent Extraction Principles and Practice, Revised and Expanded; CRC press: Boca Raton, FL, USA, 2004.

17. Pearson, R.G. Hard and Soft Acids and Bases. J. Am. Chem. Soc. 1963, 85, 3533-3539. [CrossRef]

18. Vahidi, E.; Zhao, F. Life Cycle Analysis for Solvent Extraction of Rare Earth Elements from Aqueous Solutions. In REWAS 2016: Towards Materials Resource Sustainability; Kirchain, R.E., Blanpain, B., Meskers, C., Olivetti, E., Apelian, D., Howarter, J., Kvithyld, A., Mishra, B., Neelameggham, N.R., Spangenberger, J., Eds.; Springer International Publishing: Cham, Swizerlands, 2016; pp. 113-120. [CrossRef]

19. Abbott, A.P.; Boothby, D.; Capper, G.; Davies, D.L.; Rasheed, R.K. Deep Eutectic Solvents Formed between Choline Chloride and Carboxylic Acids: Versatile Alternatives to Ionic Liquids. J. Am. Chem. Soc. 2004, 126, 9142-9147. [CrossRef]

20. Abbott, A.P.; Capper, G.; Davies, D.L.; Rasheed, R.K.; Tambyrajah, V. Novel solvent properties of choline chloride/urea mixtures. Chem. Commun. 2003, 70-71. [CrossRef]

21. Francisco, M.; van den Bruinhorst, A.; Kroon, M.C. Low-Transition-Temperature Mixtures (LTTMs): A New Generation of Designer Solvents, Angew. Chem. Int. Ed. 2013, 52, 3074-3085. [CrossRef]

22. Florindo, C.; Branco, L.C.; Marrucho, I.M. Quest for Green-Solvent Design: From Hydrophilic to Hydrophobic (Deep) Eutectic Solvents. ChemSusChem 2019, 12, 1549-1559. [CrossRef] [PubMed]

23. Rogers, R.D. CHEMISTRY: Ionic Liquids—Solvents of the Future? Science 2003, 302, 792-793. [CrossRef]

24. Paiva, A.; Craveiro, R.; Aroso, I.; Martins, M.; Reis, R.L.; Duarte, A.R.C. Natural Deep Eutectic Solvents-Solvents for the 21st Century. ACS Sustain. Chem. Eng. 2014, 2, 1063-1071. [CrossRef]

25. De los Fernández, M.Á.; Boiteux, J.; Espino, M.; Gomez, F.J.V.; Silva, M.F. Natural deep eutectic solvents-mediated extractions: The way forward for sustainable analytical developments. Anal. Chim. Acta 2018, 1038, 1-10. [CrossRef]

26. Li, X.; Row, K.H. Development of deep eutectic solvents applied in extraction and separation: Liquid Chromatography. J. Sep. Sci. 2016, 39, 3505-3520. [CrossRef] [PubMed]

27. Makoś, P.; Słupek, E.; Gębicki, J. Hydrophobic deep eutectic solvents in microextraction techniques-A review. Microchem. J. 2020, 152, 104384. [CrossRef]

28. Perna, F.M.; Vitale, P.; Capriati, V. Deep eutectic solvents and their applications as green solvents. Curr. Opin. Green Sustain. Chem. 2020, 21, 27-33. [CrossRef]

29. Shishov, A.; Bulatov, A.; Locatelli, M.; Carradori, S.; Andruch, V. Application of deep eutectic solvents in analytical chemistry. A Review. Microchem. J. 2017, 135, 33-38. [CrossRef]

30. Smith, E.L.; Abbott, A.P.; Ryder, K.S. Deep Eutectic Solvents (DESs) and Their Applications. Chem. Rev. 2014, 114, 11060-11082. [CrossRef]

31. Tang, B.; Zhang, H.; Row, K.H. Application of deep eutectic solvents in the extraction and separation of target compounds from various samples: Other Techniques. J. Sep. Sci. 2015, 38, 1053-1064. [CrossRef]

32. Zainal-Abidin, M.H.; Hayyan, M.; Hayyan, A.; Jayakumar, N.S. New horizons in the extraction of bioactive compounds using deep eutectic solvents: A review. Anal. Chim. Acta 2017, 979, 1-23. [CrossRef]

33. Silva, J.M.; Reis, R.L.; Paiva, A.; Duarte, A.R.C. Design of Functional Therapeutic Deep Eutectic Solvents Based on Choline Chloride and Ascorbic Acid. ACS Sustain. Chem. Eng. 2018, 6, 10355-10363. [CrossRef]

34. Richter, J.; Ruck, M. Synthesis and Dissolution of Metal Oxides in Ionic Liquids and Deep Eutectic Solvents. Molecules 2019, 25, 78. [CrossRef] [PubMed]

35. Tran, M.K.; Rodrigues, M.-T.F.; Kato, K.; Babu, G.; Ajayan, P.M. Deep eutectic solvents for cathode recycling of Li-ion batteries. Nat. Energy 2019, 4, 339-345. [CrossRef]

36. Cojocaru, P.; Magagnin, L.; Gomez, E.; Vallés, E. Using deep eutectic solvents to electrodeposit CoSm films and nanowires. Mater. Lett. 2011, 65, 3597-3600. [CrossRef] 
37. Pollet, B.G.; Hihn, J.-Y.; Mason, T.J. Sono-electrodeposition (20 and 850 kHz) of copper in aqueous and deep eutectic solvents. Electrochim. Acta 2008, 53, 4248-4256. [CrossRef]

38. Bahadori, L.; Chakrabarti, M.H.; Mjalli, F.S.; AlNashef, I.M.; Manan, N.S.A.; Hashim, M.A. Physicochemical properties of ammonium-based deep eutectic solvents and their electrochemical evaluation using organometallic reference redox systems. Electrochim. Acta 2013, 113, 205-211. [CrossRef]

39. Tereshatov, E.E.; Boltoeva, Y.M.; Folden, C.M. First evidence of metal transfer into hydrophobic deep eutectic and low-transition-temperature mixtures: Indium extraction from hydrochloric and oxalic acids. Green Chem. 2016, 18, 4616-4622. [CrossRef]

40. Dwamena, A.K. Recent Advances in Hydrophobic Deep Eutectic Solvents for Extraction. Separations 2019, 6, 9. [CrossRef]

41. Abbott, A.P.; Capper, G.; Davies, D.L.; McKenzie, K.J.; Obi, S.U. Solubility of Metal Oxides in Deep Eutectic Solvents Based on Choline Chloride. J. Chem. Eng. Data 2006, 51, 1280-1282. [CrossRef]

42. Binnemans, K.; Jones, P.T. Solvometallurgy: An Emerging Branch of Extractive Metallurgy. J. Sustain. Metall. 2017, 3, 570-600. [CrossRef]

43. Abbott, A.P.; Collins, J.; Dalrymple, I.; Harris, R.C.; Mistry, R.; Qiu, F.; Scheirer, J.; Wise, W.R. Processing of Electric Arc Furnace Dust using Deep Eutectic Solvents. Aust. J. Chem. 2009, 62, 341. [CrossRef]

44. Rodriguez Rodriguez, N.; Machiels, L.; Binnemans, K. Toluenesulfonic Acid-Based Deep-Eutectic Solvents for Solubilizing Metal Oxides. ACS Sustain. Chem. Eng. 2019, 7, 3940-3948. [CrossRef]

45. Entezari-Zarandi, A.; Larachi, F. Selective dissolution of rare-earth element carbonates in deep eutectic solvents. J. Rare Earths 2019, 37, 528-533. [CrossRef]

46. Riaño, S.; Petranikova, M.; Onghena, B.; Vander Hoogerstraete, T.; Banerjee, D.; StForeman, M.R.J.; Ekberg, C.; Binnemans, K. Separation of rare earths and other valuable metals from deep-eutectic solvents: A new alternative for the recycling of used NdFeB magnets. RSC Adv. 2017, 7, 32100-32113. [CrossRef]

47. Bakkar, A. Recycling of electric arc furnace dust through dissolution in deep eutectic ionic liquids and electrowinning. J. Hazard. Mater. 2014, 280, 191-199. [CrossRef] [PubMed]

48. Bakkar, A.; Neubert, V. Recycling of cupola furnace dust: Extraction and electrodeposition of zinc in deep eutectic solvents. J. Alloys Compd. 2019, 771, 424-432. [CrossRef]

49. Mukhopadhyay, S.; Mukherjee, S.; Adnan, N.F.; Hayyan, A.; Hayyan, M.; Hashim, M.A.; Sen Gupta, B. Ammonium-based deep eutectic solvents as novel soil washing agent for lead removal. Chem. Eng. J. 2016, 294, 316-322. [CrossRef]

50. Petračić, A.; Sander, A.; Cvetnić, M. A novel approach for the removal of trace elements from waste fats and oils. Sep. Sci. Technol. 2019, 1-15. [CrossRef]

51. Zürner, P.; Frisch, G. Leaching and Selective Extraction of Indium and Tin from Zinc Flue Dust Using an Oxalic Acid-Based Deep Eutectic Solvent. ACS Sustain. Chem. Eng. 2019, 7, 5300-5308. [CrossRef]

52. Jenkin, G.R.T.; Al-Bassam, Z.M.A.; Harris, R.C.; Abbott, A.P.; Smith, D.J.; Holwell, D.A.; Chapman, R.J.; Stanley, C.J. The application of deep eutectic solvent ionic liquids for environmentally-friendly dissolution and recovery of precious metals. Miner. Eng. 2016, 87, 18-24. [CrossRef]

53. Peeters, N.; Binnemans, K.; Riaño, S. Solvometallurgical recovery of cobalt from lithium-ion battery cathode materials using deep-eutectic solvents. Green Chem. 2020, 22, 4210-4221. [CrossRef]

54. Wang, S.; Zhang, Z.; Lu, Z.; Xu, Z. A novel method for screening deep eutectic solvent to recycle the cathode of Li-ion batteries. Green Chem. 2020, 22, 4473-4482. [CrossRef]

55. Zeng, X.; Li, J.; Shen, B. Novel approach to recover cobalt and lithium from spent lithium-ion battery using oxalic acid. J. Hazard. Mater. 2015, 295, 112-118. [CrossRef] [PubMed]

56. Lee, C.K.; Rhee, K.-I. Preparation of LiCoO2 from spent lithium-ion batteries. J. Power Sources 2002, 109, 17-21. [CrossRef]

57. Cui, Y.; Li, C.; Yin, J.; Li, S.; Jia, Y.; Bao, M. Design, synthesis and properties of acidic deep eutectic solvents based on choline chloride. J. Mol. Liq. 2017, 236, 338-343. [CrossRef]

58. Albler, F.-J.; Bica, K.; StForeman, M.R.J.; Holgersson, S.; Tyumentsev, M.S. A comparison of two methods of recovering cobalt from a deep eutectic solvent: Implications for battery recycling. J. Clean. Prod. 2017, 167, 806-814. [CrossRef] 
59. Ghareh Bagh, F.S.; Mjalli, F.S.; Hashim, M.A.; Hadj-Kali, M.K.O.; AlNashef, I.M. Solubility of Sodium Salts in Ammonium-Based Deep Eutectic Solvents. J. Chem. Eng. Data 2013, 58, 2154-2162. [CrossRef]

60. Gupta, R.; Vats, B.; Pandey, A.K.; Sharma, M.K.; Sahu, P.; Yadav, A.K.; Ali, M.; Kannan, S. Insight into Speciation and Electrochemistry of Uranyl Ions in Deep Eutectic Solvents. J. Phys. Chem. B 2020, 124, 181-189. [CrossRef]

61. Poll, C.G.; Nelson, G.W.; Pickup, D.M.; Chadwick, A.V.; Riley, D.J.; Payne, D.J. Electrochemical recycling of lead from hybrid organic-inorganic perovskites using deep eutectic solvents. Green Chem. 2016, 18, 2946-2955. [CrossRef]

62. Almeida, J.; Craveiro, R.; Faria, P.; Silva, A.S.; Mateus, E.P.; Barreiros, S.; Paiva, A.; Ribeiro, A.B. Electrodialytic removal of tungsten and arsenic from secondary mine resources-Deep eutectic solvents enhancement. Sci. Total Environ. 2020, 710, 136364. [CrossRef]

63. Yang, H.; Reddy, R.G. Electrochemical deposition of zinc from zinc oxide in 2:1 urea/choline chloride ionic liquid. Electrochim. Acta 2014, 147, 513-519. [CrossRef]

64. Mandroyan, A.; Mourad-Mahmoud, M.; Doche, M.-L.; Hihn, J.-Y. Effects of ultrasound and temperature on copper electro reduction in Deep Eutectic Solvents (DES). Ultrason. Sonochem. 2014, 21, 2010-2019. [CrossRef] [PubMed]

65. Florindo, C.; Romero, L.; Rintoul, I.; Branco, L.C.; Marrucho, I.M. From Phase Change Materials to Green Solvents: Hydrophobic Low Viscous Fatty Acid-Based Deep Eutectic Solvents. ACS Sustain. Chem. Eng. 2018, 6, 3888-3895. [CrossRef]

66. Shi, Y.; Xiong, D.; Zhao, Y.; Li, T.; Zhang, K.; Fan, J. Highly efficient extraction/separation of Cr (VI) by a new family of hydrophobic deep eutectic solvents. Chemosphere 2020, 241, 125082. [CrossRef] [PubMed]

67. Ruggeri, S.; Poletti, F.; Zanardi, C.; Pigani, L.; Zanfrognini, B.; Corsi, E.; Dossi, N.; Salomäki, M.; Kivelä, H.; Lukkari, J.; et al. Chemical and electrochemical properties of a hydrophobic deep eutectic solvent. Electrochim. Acta 2019, 295, 124-129. [CrossRef]

68. Phelps, T.E.; Bhawawet, N.; Jurisson, S.S.; Baker, G.A. Efficient and Selective Extraction of 99mTcO4- from Aqueous Media Using Hydrophobic Deep Eutectic Solvents. ACS Sustain. Chem. Eng. 2018, 6, 13656-13661. [CrossRef]

69. Van Osch, D.J.G.P.; Parmentier, D.; Dietz, C.H.J.T.; van den Bruinhorst, A.; Tuinier, R.; Kroon, M.C. Removal of alkali and transition metal ions from water with hydrophobic deep eutectic solvents. Chem. Commun. 2016, 52, 11987-11990. [CrossRef]

70. Ola, P.D.; Matsumoto, M. Use of deep eutectic solvent as extractant for separation of Fe (III) and Mn (II) from aqueous solution. Sep. Sci. Technol. 2019, 54, 759-765. [CrossRef]

71. Schaeffer, N.; Conceição, J.H.F.; Martins, M.A.R.; Neves, M.C.; Pérez-Sánchez, G.; Gomes, J.R.B.; Papaiconomou, N.; Coutinho, J.A.P. Non-ionic hydrophobic eutectics-Versatile solvents for tailored metal separation and valorisation. Green Chem. 2020. [CrossRef]

72. Schaeffer, N.; Martins, M.A.R.; Neves, C.M.S.S.; Pinho, S.P.; Coutinho, J.A.P. Sustainable hydrophobic terpene-based eutectic solvents for the extraction and separation of metals. Chem. Commun. 2018, 54, 8104-8107. [CrossRef]

73. Gilmore, M.; McCourt, É.N.; Connolly, F.; Nockemann, P.; Swadźba-Kwaśny, M.; Holbrey, J.D. Hydrophobic Deep Eutectic Solvents Incorporating Trioctylphosphine Oxide: Advanced Liquid Extractants. ACS Sustain. Chem. Eng. 2018, 6, 17323-17332. [CrossRef]

74. Arain, M.B.; Yilmaz, E.; Soylak, M. Deep eutectic solvent based ultrasonic assisted liquid phase microextraction for the FAAS determination of cobalt. J. Mol. Liq. 2016, 224, 538-543. [CrossRef]

75. Preston, J.S. Solvent extraction of metals by carboxylic acids. Hydrometallurgy 1985, 14, 171-188. [CrossRef]

76. Cartoni, G.P.; Liberti, A.; Palombari, R. Metal complexes of $\beta$-diketones as liquid phases in gas-Liquid chromatography. J. Chromatogr. A 1965, 20, 278-282. [CrossRef]

77. Van den Bruinhorst, A.; Raes, S.; Atika Maesara, S.; Kroon, M.C.; Esteves, A.C.C.; Meuldijk, J. Hydrophobic Eutectic Mixtures as Volatile Fatty Acid Extractants. Sep. Purif. Technol. 2019, 216, 147-157. [CrossRef]

78. Van Osch, D.J.G.P.; Zubeir, L.F.; van den Bruinhorst, A.; Rocha, M.A.A.; Kroon, M.C. Hydrophobic deep eutectic solvents as water-immiscible extractants. Green Chem. 2015, 17, 4518-4521. [CrossRef] 
79. Dupont, D.; Depuydt, D.; Binnemans, K. Overview of the Effect of Salts on Biphasic Ionic Liquid/Water Solvent Extraction Systems: Anion Exchange, Mutual Solubility, and Thermomorphic Properties. J. Phys. Chem. B 2015, 119, 6747-6757. [CrossRef]

80. Kudłak, B.; Owczarek, K.; Namieśnik, J. Selected issues related to the toxicity of ionic liquids and deep eutectic solvents-A review. Environ. Sci. Pollut. Res. 2015, 22, 11975-11992. [CrossRef] [PubMed]

Publisher's Note: MDPI stays neutral with regard to jurisdictional claims in published maps and institutional affiliations.

(C) 2020 by the authors. Licensee MDPI, Basel, Switzerland. This article is an open access article distributed under the terms and conditions of the Creative Commons Attribution (CC BY) license (http://creativecommons.org/licenses/by/4.0/). 